\title{
Developing clinical practice guidelines for caries prevention and management for pre-school children through the ADAPTE process and Delphi consensus
}

\author{
Gillian H. M. Lee ${ }^{1 *}$, Colman McGrath ${ }^{2}$ and Cynthia K. Y. Yiu ${ }^{1}$
}

\begin{abstract}
Background: This study aims to develop consensus evidence-based clinical guidelines for caries prevention and management by caries risk assessment for pre-school children in Hong Kong.

Methods: Employing the ADAPTE process, guidelines for caries prevention and management by caries risk assessment for pre-school children with a preliminary list of 91 recommendations was complied. External review of the guidelines was conducted by a panel of 41 reviewers from the Hong Kong Society of Paediatric Dentistry using a two-round web-based Delphi process. The reviewers were invited to contribute any comments on the draft-adapted guidelines and rated their agreement with each recommendation using a 9-point Likert scale. During the second round, 36 participants received anonymous feedback from the first round and assessed a narrowed list of 28 recommendations. Recommendations were retained and classified according to the median score and rating percentages by the reviewers.

Results: A total of 70 out of 91 recommendations were retained (five reached high consensus, 65 reached consensus), and 21 recommendations were discarded. Recommendations and guidelines were outlined.

Conclusions: Caries prevention and management guidelines for pre-school children were developed for use in Hong Kong using the ADAPTE process and Delphi consensus to develop evidence-based recommendations. This can facilitate the translation of guidelines into dental practice.
\end{abstract}

Keywords: Guidelines, Guidelines development, ADAPTE, Delphi consensus, Oral health, Children, Caries risk assessment, Dental caries, Prevention

\section{Background}

Dental caries in pre-school children remains a problem in Hong Kong. In a recent population-based oral health survey, the caries experience of pre-school children was over 50\% in Hong Kong, with an extensive proportion of untreated carious teeth (over 90\%) [1]. One in 20 of the children had a dental abscess associated with an extensively decayed tooth. The prevalence of dental caries among pre-school children showed limited improvement over the past decade and the extent and severity have

\footnotetext{
* Correspondence: lee.gillian@gmail.com

${ }^{1}$ Paediatric Dentistry, Faculty of Dentistry, University of Hong Kong, 2/F,

Prince Philip Dental Hospital, 34 Hospital Road, Hong Kong, China

Full list of author information is available at the end of the article
}

increased. Among pre-school children, the number of decayed, missing and filled teeth was 2.3 in 2001 and 2.5 in 2011 [1, 2]. Children from disadvantaged and socially marginalised populations have even higher caries experience and are at higher risk for caries.

The high degree of untreated dental caries indicates that there is inadequate access to quality oral healthcare for pre-school children in Hong Kong. Management of pre-school children's oral health requires commitment from professionals, patients and their families. Dentists' attitudes can contribute to the problem, resulting in a barrier to provide adequate and quality dental care [3]. Dentists in Hong Kong do see the value of dental treatment for pre-school children, but most general dental practitioners consider children's coping skills to dental 
treatment as a problem and have a negative attitude towards the provision of dental care for children [4]. A wide variation in caries management approaches among dental practitioners has also been identified [5], reflecting the uncertainty within the profession about the most suitable and effective dental care approaches for preschool children with dental caries. Thus, these factors highlight the need for clinical guidelines relating to dental caries for pre-school children in Hong Kong.

Clinical practice guidelines are systematically developed statements that can assist practitioners and patients in making decisions about appropriate healthcare for specific clinical circumstances [6,7]. It is the major available tool to assist in the translating of research evidence into practice. With the best available evidence and opinion in guidelines, healthcare professionals can be assisted in making appropriate clinical decisions, minimising variation in practice, and promote effective and safe patient outcomes.

Expectations and requirements have been proposed internationally for the development of quality clinical guidelines $[8,9]$. The development and implementation of guidelines that meet international standards require substantial time, expertise and resources, especially during systematic identification and critical analysis of evidence. Guideline adaptation is a systematic approach for considering the endorsement or modification of guidelines produced in one setting for application and implementation in another as an alternative to de novo guideline development or as a first step in the process of implementation, while preserving evidence-based principles [10]. The ADAPTE process is a comprehensive framework for guideline adaptation. ADAPTE can reduce duplication of effort and enhance efficiency in guideline development. The manual and toolkit for the ADAPTE process are available at: http://www.g-i-n.net/ gin [11]. The ADAPTE process consists of three main phases: set up, adaptation and finalisation.

The Delphi technique is a formal iterative structured process that aims to gather consensus of opinion, judgement or choice among a panel of experts [12-15]. The attitudes, needs and priorities of the panel can be explored during the interactive process. Delphi is suitable for reaching consensus on topics with dissenting opinions, uncertainty or absence of evidence. Guidelines developed with consensus of stakeholders are more likely to be accepted by the dental profession.

There are several quality guidelines for managing dental caries for pre-school children worldwide. Nevertheless, guidelines ascribed to other countries or areas can encounter barriers to their practical application in a context with a different culture and healthcare system [16]. Localised or adapted clinical guidelines on the basis of available evidence in the local context are advocated, with the consideration of cost-effectiveness and suitability for the local population. This project aims to develop consensus evidence-based clinical guidelines to inform the practice regarding the determination of caries risk and developing preventive and management strategies for pre-school children in Hong Kong using the ADAPTE process and a web-based Delphi consensus technique.

\section{Methods \\ Set up phase}

The project was led by a team of researchers based at the Faculty of Dentistry, the University of Hong Kong. The team comprised of specialists in the field of Dental Public Health and Paediatric Dentistry. Members of the team reported no conflict of interests. The scope and key questions for the guidelines were established. The key stakeholder, the Hong Kong Society of Paediatric Dentistry (HKSPD), was identified and invited to be the collaborator on developing the guidelines. An introduction to guideline development and the ADAPTE process was presented to the members of the Society.

\section{Adaptation phase \\ Search and screen guidelines}

A search for relevant guidelines, protocols or policy statements in guideline repository websites, websites of various key guideline development organisations, and dental professional organisations, plus MEDLINE (Ovid), PubMed, Google and several other databases was conducted. The subject heading 'dental caries' was used for the search in combination with several other keyword terms: 'tooth decay' or 'diagnosis' or 'management' or 'prevention' or 'approach' or 'caries risk' or 'caries risk assessment' or 'caries assessment' or 'caries prediction' or 'children'. An appropriate search strategy for each database was employed.

Twenty non-duplicate guidelines, protocols or policy statements were identified in the search. No language restrictions were applied at this point. The retrieved guidelines were screened according to list of a priori inclusion/exclusion criteria: (1) dental caries, regarding its diagnosis, prevention, management or risk assessment was the main topic of the guidelines; (2) the target population of the guidelines was pre-school children with primary dentition; (3) the guidelines were for local or national use; (4) publication date should be from 2000 onwards to date of the search (December 2011); (5) indication that a literature search, ideally using a systematic method, had been conducted; (6) references were included; and (7) explicit link between the recommendations and the supporting evidence was indicated. 


\section{Access guidelines}

Eleven guidelines/protocols were retained for further assessment after initial screening based on the inclusion/ exclusion criteria. A panel group with four clinical teaching staff from the Department of Paediatric Dentistry of the University of Hong Kong was set up. The panel members were briefed about the guideline development and evaluation process for the retrieved guidelines by the guideline development group. They were invited to review the 11 retrieved guidelines and appraise their quality using the AGREE II (Appraisal of Guidelines for Research and Evaluation II) instrument individually [17]. The AGREE II instrument is a generic instrument to assess the process of guideline development and reporting of this process in the guidelines. The instrument consists of 23 items on a 7-point response scale comprising six quality-related domains: scope and purpose, stakeholder involvement, rigour of development, clarity of presentation, applicability, and editorial independence. The instrument's overall assessment includes the rating of the overall quality of the guideline and whether the guideline would be recommended for use in practice. The scores for each of the six AGREE II domains of each of the retrieved guidelines were calculated according to the rubrics. Pooled domain scores and overall assessment scores for the 11 guidelines are presented in Table 1.

Three 'Source' guidelines for adaptation in the ADAPTE process were selected [18-20]. The selection was based on the AGREE II scores on Domain 3 (rigour of development) and overall assessment scores. The currency of the guidelines, applicability and extent of the key questions for the guidelines were also taken into account. Although the Scottish Dental Effectiveness
Programme 2010 [21] had higher scores than American Academy of Pediatric Dentistry 2011 [20], the guideline was not selected because the content and extent of key questions covered was very similar to the Scottish Intercollegiate Guidelines Network (SIGN) 2005 [18]. Therefore, the next guideline on the list, that of American Academy of Pediatric Dentistry 2011 [20], was selected. The three 'source' guidelines provided different perspectives on caries prevention and management strategies and on caries risk assessment, and together addressed most of the key questions for the developing guidelines. With regard to the clarity of presentation of the guidelines, the other three retrieved guidelines [21-23] were kept as 'satellite' for reference.

\section{Drafting of guidelines}

The recommendations from the three source guidelines were compiled in a recommendation matrix and compared. The grading and levels of evidence associated with each of the recommendations provided by the source guidelines were placed within each cell and was critically appraised using the SIGN methodology checklist [24].

The consistency between the evidence presented in the source guidelines, their interpretation of the evidence, and the resulting recommendations were evaluated. The original evidence supporting the interpretations and recommendations in the source guidelines were reviewed. The currency of the source guidelines for the adaptation process was also assessed to ascertain whether the most current evidence had been included.

A literature search of databases and websites for systematic reviews and randomised clinical trials, quasirandomised trials or longitudinal cohort studies since

Table 1 The six AGREE II domain scores and overall assessment scores of the 11 retrieved guidelines

\begin{tabular}{lccccccc}
\hline Retrieved guidelines & \multicolumn{3}{l}{ Scaled domain score } & & & & \\
\cline { 2 - 7 } & Domain 1 & Domain 2 & Domain 3 & Domain 4 & Domain 5 & Domain 6 & Overall \\
\hline Scottish Intercollegiate Guidelines Network, 2005 [18] & 72.22 & 69.44 & 59.38 & 63.89 & 61.46 & 54.17 & 66.67 \\
American Dental Association Council on Scientific Affairs, 2006 [33] & 63.89 & 56.94 & 53.13 & 68.06 & 47.92 & 64.58 & 58.33 \\
Ramos-Gomez et al., 2007 [34] & 72.22 & 58.33 & 43.23 & 61.11 & 50.00 & 35.42 & 54.17 \\
Irish Oral Health Services Guideline Initiative, 2008 [22] & 93.06 & 77.78 & 80.73 & 81.94 & 67.71 & 64.58 & 83.33 \\
Swedish Council on Technology Assessment in Health Care (SBU), & 65.28 & 51.39 & 53.13 & 56.94 & 50.00 & 37.50 & 54.17 \\
2008 [35] & & & & & & \\
American Academy of Pediatric Dentistry, 2009 [36] & 59.72 & 36.11 & 30.73 & 47.22 & 36.46 & 43.75 & 45.83 \\
Irish Oral Health Services Guideline Initiative, 2009 [19] & 91.67 & 65.28 & 79.69 & 79.17 & 63.54 & 72.92 & 79.17 \\
Scottish Dental Effectiveness Programme, 2010 [21] & 76.39 & 69.44 & 60.94 & 72.22 & 65.63 & 66.67 & 70.83 \\
Ramos-Gomez et al., 2010 [37] & 68.06 & 55.56 & 47.40 & 59.72 & 54.17 & 43.75 & 54.17 \\
American Academy of Pediatric Dentistry, 2011 [20] & 76.39 & 66.67 & 56.77 & 66.67 & 52.08 & 41.67 & 62.50 \\
Ramos-Gomez and Ng, 2011 [23] & 72.22 & 63.89 & 58.33 & 62.50 & 51.04 & 39.58 & 54.17 \\
\hline
\end{tabular}

Domain 1 - Scope \& Purpose; Domain 2 - Stakeholder Involvement; Domain 3 - Rigour of Development; Domain 4 - Clarity of Presentation; Domain 5 Applicability; Domain 6 - Editorial Independence; Overall - Overall assessment 
the source guidelines published was conducted. The relevant publications were critically appraised and graded. The publications searched were between 2004 and June 2012. Year 2004 was the end date of search in the oldest source guideline by SIGN [18]. This limited search period was established to identify new publications that were not included in the three 'source' guidelines. The search was later updated to the period between 2004 and December 2012 following external review for the preparation of the final guidelines.

Draft-adapted/adopted recommendations and summaries of the evidence were assessed by the guideline development group for (1) consistency between the evidence presented, (2) its interpretation and the resulting adapted/adopted recommendations, and (3) the effect of any new evidence on the recommendations. For each of the draft-adapted/adopted recommendations, their acceptability and applicability in the local Hong Kong context, taking culture, organisation and expertise of dental services and population characteristic, beliefs and values into account, were discussed and considered in the meetings among the guideline development group. Using informal consensus, the recommendations were either adapted, updated or rejected based on the latest evidence identified. A preliminary list of 91 draft recommendations was developed.

\section{Finalisation phase}

A consultation draft of the adapted guidelines was produced with the preliminary list of $91 \mathrm{draft}$ recommendations. The draft was circulated among the guideline development group members for comment and was revised where necessary.

\section{External review process}

All 68 ordinary and associate members (excluding guideline development group members and panel members) of the HKSPD (key stakeholder) were invited to be external reviewers by email. Ordinary HKSPD members were either registered paediatric dentists or practitioners who had completed structured training in the specialty and were experts in Paediatric Dentistry in Hong Kong. Associate members of HKSPD were general medical or dental practitioners who were interested in the practice of Paediatric Dentistry. All of them would be the potential users of the developing guidelines.

Electronic copies of the consultation draft of the adapted guidelines were circulated to the external reviewers. The external reviewers were invited to contribute any comments on the consultation draft of the developing guidelines. An Internet-based structured questionnaire on a 5-point Likert scale was used to ask the external reviewers about their view on the strengths and weaknesses of the consultation draft, any need for modification, whether they would approve the draft guidelines and use them in their practice, and how it would impact or change their current practice. The 22 items about the external reviewers' general view on the guidelines were added up to create a general view score ranging from 0 to 110 , with a higher score indicating a more positive attitude towards the guidelines. The external reviewers consented to participate in the guideline external review process and for the data to be published.

\section{Ranking of recommendations}

A two-round Internet-based password-protected Delphi consensus process was conducted among the external reviewers. The Delphi process was carried out to collect opinions or comments from external reviewers so as to establish consensus recommendations for the guidelines. Before each round, external reviewers were reminded of the upcoming surveys by at least four emails. The draft recommendations were presented to the external reviewers. They rated their agreement with each of the 91 preliminary adapted/adopted recommendations using a 9-point Likert scale ( $1=$ strongly disagree, $5=$ no opinion or not enough information or experience to judge, $9=$ strongly agree) and to contribute any comments on the recommendations. They were given the option of not commenting on a recommendation when the topic was outside their respective areas of expertise. This process was repeated during the second round, in which reviewers' ratings, dissenting opinions or uncertainty, or absence of evidence were combined and provided anonymously to all of them. They were allowed to revise their first round responses in view of further responses in the second round. After the first round, the guideline development group met to modify some recommendations for clarity and presentation for the second round.

\section{Classification of recommendations}

For the first round of Delphi, recommendations rated by $<20 \%$ of the external reviewers were discarded. Recommendations rated by $80 \%$ of the external reviewers were discarded if the overall median score fell within the bottom tertile (1-3, disagree) and deferred until the second round if the overall median score was 4-6 (neutral). Recommendations with overall median scores within the top tertile (7-9) were classified as follows: those rated by $<80 \%$ of the external reviewers were deferred until the second round, and those rated by $\geq$ $80 \%$ of the external reviewers were classified as 'high agreement' if they had an overall median score of 9 or as 'agreement' they had an overall median score of 7 or 8 .

Similarly, in the second round of Delphi, recommendations rated by $<20 \%$ of the external reviewers were discarded. Recommendations rated by $80 \%$ of the external reviewers were discarded if the overall median score 
fell between 1 and 6. Recommendations with an overall median score within the top tertile (7-9) were classified as follows: those rated by $<80 \%$ of the external reviewers were discarded, and those rated by $\geq 80 \%$ of the external reviewers were classified as for the first round. The classification of recommendations according to the overall median score and percentage of ratings by external reviewers in the two-round Delphi process is illustrated in Fig. 1.

\section{Data analysis}

Data were analysed using IBM $^{\bullet}$ SPSS Statistics 19 (SPSS Inc., Chicago, IL, USA). Recommendationspecific medians were estimated for each round. The inter-rater agreement between participants in each round was evaluated using intraclass correlation coefficient with 95\% confidence intervals (CI). Microsoft Excel for Mac 2011 was used for preparing tabular and graphic presentation.

\section{Production of the final guideline}

All the feedback from the external reviewers were documented and presented in the guideline development group meeting for discussion. The guidelines and recommendations were further revised to incorporate feedback from the external reviewers where necessary.

\section{Results}

The flow chart in Fig. 2 describes the number of guideline recommendations and participation of external reviewers in the external review process. Forty-one out of 68 invited members agreed to participate (response rate: 41/68= $60.3 \%)$. In the Delphi process, there were 41 external reviewers in the first round and 36 for the second round (drop-out rate: $5 / 41=12.2 \%$; overall response rate: $36 / 68=$ $52.9 \%)$. The intraclass correlation coefficients were 0.96 (95\% CI, 0.95-0.98) and 0.92 (95\% CI, 0.87-0.95) for the first and second rounds, respectively.

All the participated external reviewers rated all the items. Of the original 91 recommendations, 70 were retained and classified as follows: five items reached consensus ('high agreement'), 65 items reached near consensus ('agreement'), 21 items were discarded. Results of the recommendations in the two-round Internet-based Delphi consensus surveys are listed in Table 2. Only those recommendations $(N=70)$ that had gained consensus from the external reviewers in the Delphi process were included in the final list of recommendations of the guidelines.

The ratings of the external reviewers about their general views on the strengths and weaknesses of the guidelines are listed in Table 3. The majority of the external reviewers $(82.9 \%)$ agreed that there was a need for the guidelines on caries prevention and management by caries risk assessment for pre-school children in Hong Kong

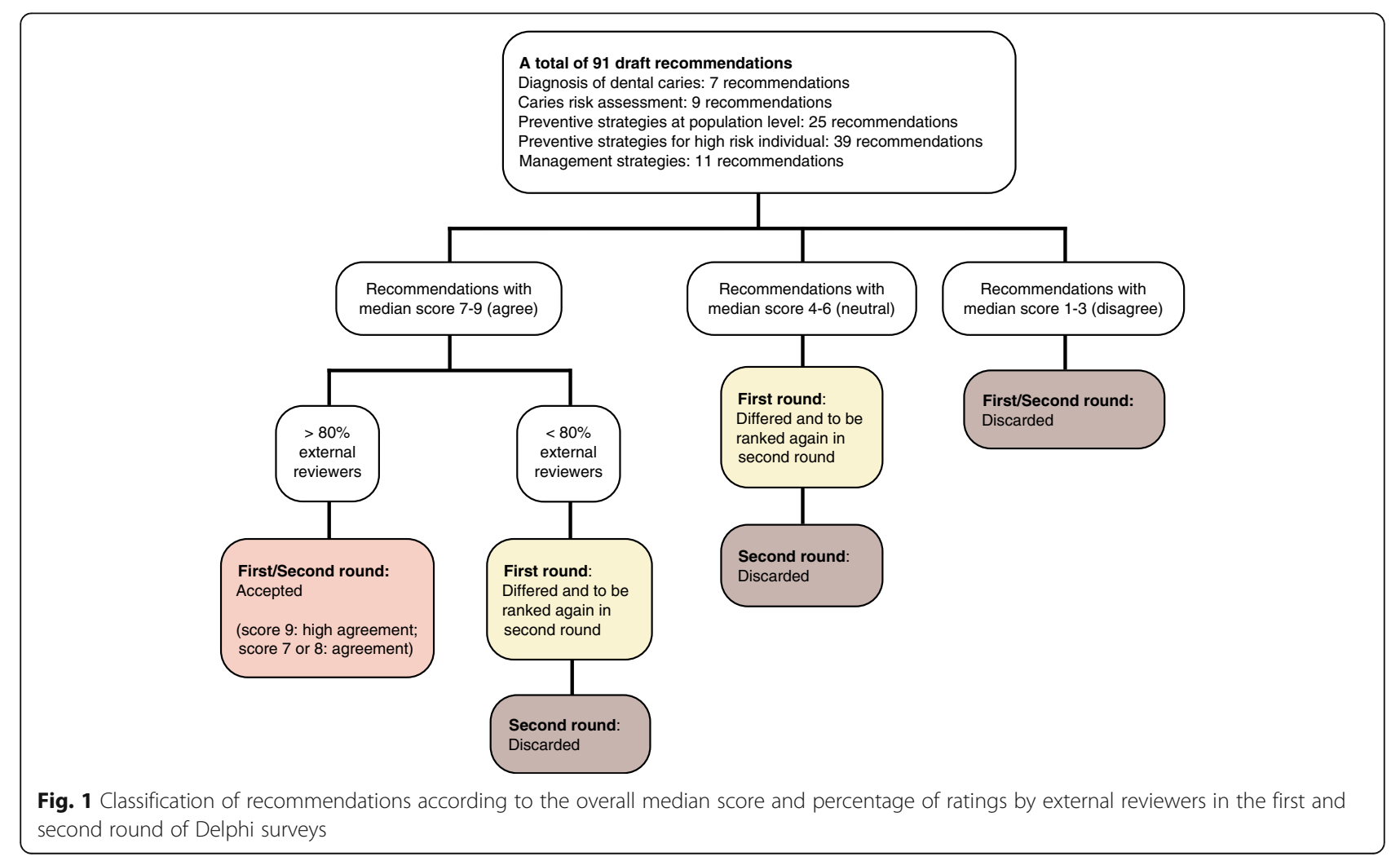




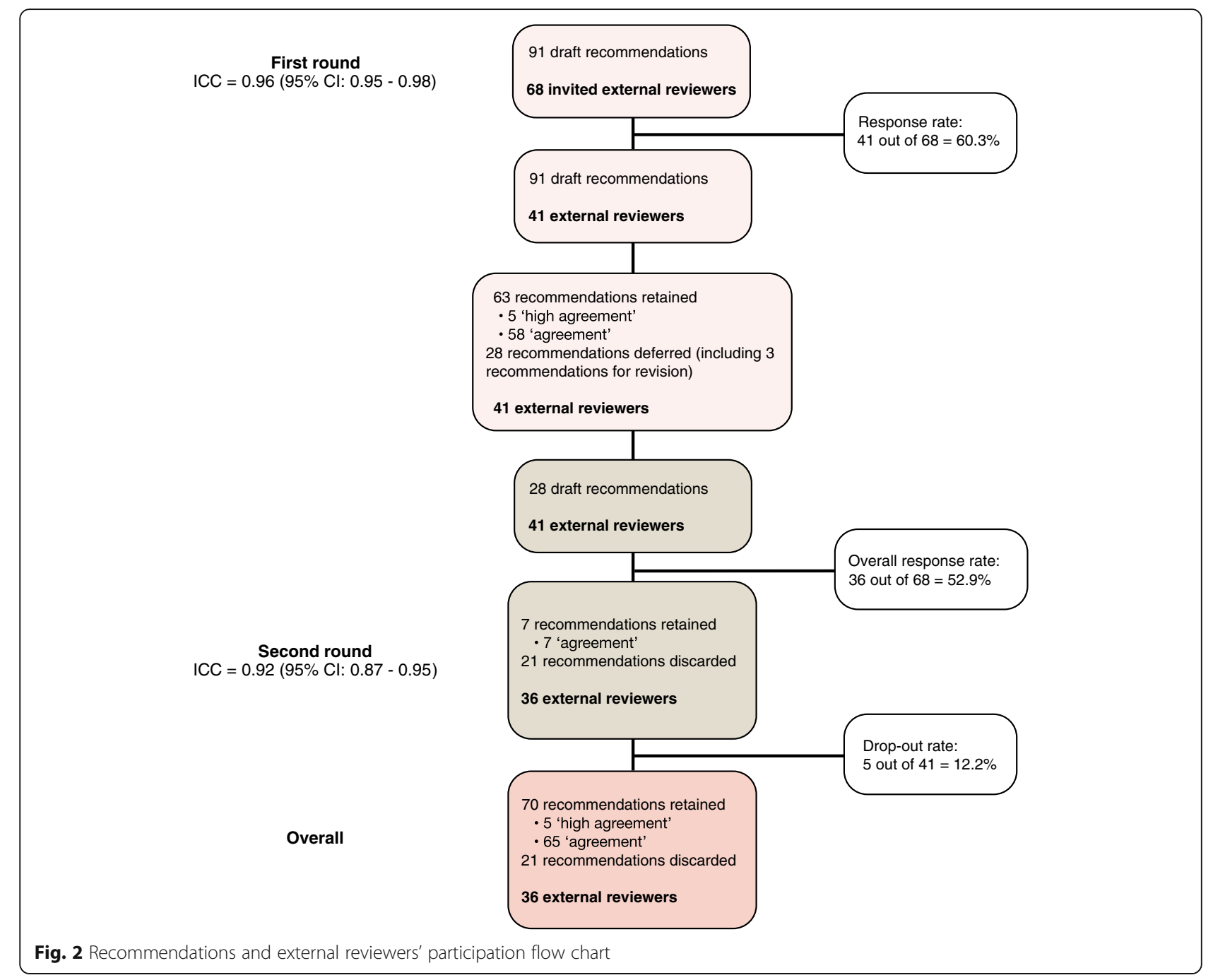

(statement 2). Over half of them ( $>60 \%)$ agreed to practice the guidelines when they are implemented (statement 21-22) and agreed that the guidelines were properly developed (statement 1, 3, 4). They were also positive about the relevance and applicability of guideline recommendations in practice and on patients (statement 5-13, 19). However, their views regarding the possible effects and outcomes of the guidelines were neutral (statement 14-18). Over $60 \%$ of the external reviewers approved the guidelines as clinical practice guidelines. The mean general view score of the guideline was 75.66 ( $\mathrm{SD}=7.80$; out of a maximum possible score of 110).

\section{Discussion}

Clinical practice guidelines are the major means to summarise and translate rapidly changing research evidence into practice and assist clinical decision making [25, 26]. Clinicians require knowledge of the current expert recommendations and guidelines to manage specific clinical problems and improve their patients' outcomes. Developing evidence-based guidelines on caries prevention and management by caries risk assessment for pre-school children in Hong Kong is important. The guidelines have great potential in improving the current oral health and dental care of pre-school children in Hong Kong if implemented.

Developing clinical practice guidelines using the ADAPTE process and Delphi consensus has not been reported in the literature. This approach allows developing guidelines with consensus evidence-based recommendations. The literature suggests that guidelines developed without active participation and involvement of the intended users and which were partially without credible scientific basis were not fully supported by the profession and were poorly accepted by the practitioners $[27,28]$. ADAPTE is a comprehensive systematic framework for adapting guidelines produced in one setting to be used in a different cultural context. The framework was developed to meet the current challenges of guideline development and 
Table 2 Results of the recommendations of the adapted guidelines in the two-round Delphi survey

\begin{tabular}{|c|c|c|c|c|c|}
\hline Topic & No. & Recommendations & $\begin{array}{l}\text { First round }^{a} \\
\text { Median Score (\%) }\end{array}$ & $\begin{array}{l}\text { Second round } \\
\text { Median Score (\%) }\end{array}$ & Final decision \\
\hline \multirow[t]{7}{*}{$\begin{array}{l}\text { Diagnosis of dental caries } \\
(N=7)\end{array}$} & 1 & $\begin{array}{l}\text { Caries should be diagnosed as early as possible } \\
\text { to allow management before cavitation and } \\
\text { pulpal involvement, and to identify caries-active } \\
\text { patients and those at increased risk of caries in } \\
\text { the future }\end{array}$ & $8,100 \%$ & - & $\begin{array}{l}\text { retained as } \\
\text { 'agreement' }\end{array}$ \\
\hline & 2 & $\begin{array}{l}\text { New caries detection systems, like Diagnodent, } \\
\text { DIFOTI and QLF, can be used as an adjunct } \\
\text { diagnostic method in addition to the traditional } \\
\text { clinical and radiographic examination }\end{array}$ & $7,53.7 \%$ & $7,52.8 \%$ & discarded \\
\hline & 3 & $\begin{array}{l}\text { A thorough clinical examination should be } \\
\text { carried out on clean dried teeth }\end{array}$ & $8,87.8 \%$ & - & $\begin{array}{l}\text { retained as } \\
\text { 'agreement' }\end{array}$ \\
\hline & 4 & $\begin{array}{l}\text { As thorough a caries diagnostic examination } \\
\text { should be performed as the child's level of } \\
\text { cooperation permits }\end{array}$ & $8,87.8 \%$ & - & $\begin{array}{l}\text { retained as } \\
\text { 'agreement' }\end{array}$ \\
\hline & 5 & $\begin{array}{l}\text { The use of bitewing radiography for caries } \\
\text { diagnosis should be considered for pre-school } \\
\text { children attending for dental care, particularly } \\
\text { if they are assessed as being at increased risk } \\
\text { of dental caries }\end{array}$ & $6,48.8 \%$ & $6.5,50.0 \%$ & discarded \\
\hline & 6 & $\begin{array}{l}\text { The timing of subsequent radiographic } \\
\text { examinations should be based on the patient's } \\
\text { caries risk status }\end{array}$ & $8,90.2 \%$ & - & $\begin{array}{l}\text { retained as } \\
\text { 'agreement' }\end{array}$ \\
\hline & 7 & $\begin{array}{l}\text { Practitioners should receive training in clinical } \\
\text { and radiographic caries diagnosis }\end{array}$ & $8,87.8 \%$ & - & $\begin{array}{l}\text { retained as } \\
\text { 'agreement' }\end{array}$ \\
\hline \multirow[t]{7}{*}{ Caries risk assessment $(N=9)$} & 8 & $\begin{array}{l}\text { The use of a practical caries risk assessment tool } \\
\text { should be implemented into practice to facilitate } \\
\text { the caries risk assessment process }\end{array}$ & $7,68.3 \%$ & $8,86.1 \%$ & $\begin{array}{l}\text { retained as } \\
\text { 'agreement' }\end{array}$ \\
\hline & 9 & $\begin{array}{l}\text { The caries risk assessment tool should be } \\
\text { integrated into the electronic patient record }\end{array}$ & $7,58.5 \%$ & $8,75.0 \%$ & discarded \\
\hline & 10 & $\begin{array}{l}\text { Public health nurses, practice nurses, general } \\
\text { practitioners and other primary care workers } \\
\text { who have regular contact with young children } \\
\text { should have training in the identification of } \\
\text { high caries risk pre-school children }\end{array}$ & $8,80.5 \%$ & - & $\begin{array}{l}\text { retained as } \\
\text { 'agreement' }\end{array}$ \\
\hline & 11 & $\begin{array}{l}\text { Public health nurses or other child healthcare } \\
\text { professionals should carry out a caries risk } \\
\text { assessment for children as part of their routine } \\
\text { overall health assessment and recorded in the } \\
\text { child's health record }\end{array}$ & $7,73.2 \%$ & $8,83.3 \%$ & $\begin{array}{l}\text { retained as } \\
\text { 'agreement' }\end{array}$ \\
\hline & 12 & $\begin{array}{l}\text { Referral pathways should be developed to allow } \\
\text { referral of high caries risk pre-school children } \\
\text { from primary, secondary and social care services } \\
\text { into dental services }\end{array}$ & $8,82.9 \%$ & - & $\begin{array}{l}\text { retained as } \\
\text { 'agreement' }\end{array}$ \\
\hline & 13 & $\begin{array}{l}\text { A dental practice-based caries risk assessment } \\
\text { should be carried out on individual pre-school } \\
\text { children and should include the following risk } \\
\text { indicators: - evidence of previous caries } \\
\text { experience - resident in a deprived area - } \\
\text { healthcare worker's opinion - oral mutans } \\
\text { streptococci counts (if accessible) }\end{array}$ & $7,61.0 \%$ & - & \\
\hline & 13 & $\begin{array}{l}\text { Revised in second round to: A dental practice- } \\
\text { based caries risk assessment should be carried }\end{array}$ & - & $8,80.6 \%$ & $\begin{array}{l}\text { retained as } \\
\text { 'agreement' }\end{array}$ \\
\hline
\end{tabular}
should include the following risk indicators: evidence of previous caries experience medically compromised or with special needs lower socioeconomic family background resident in a deprived area - healthcare worker's opinion - oral mutans streptococci counts (if accessible) (revised as some external 
Table 2 Results of the recommendations of the adapted guidelines in the two-round Delphi survey (Continued)

\begin{tabular}{|c|c|c|c|c|c|}
\hline & & $\begin{array}{l}\text { reviewers suggested that more caries risk factors } \\
\text { should be included) }\end{array}$ & & & \\
\hline & 14 & $\begin{array}{l}\text { A formal caries risk assessment using a structured } \\
\text { caries risk assessment tool should be done for } \\
\text { children attending the dental clinic for dental } \\
\text { assessment or emergency care }\end{array}$ & $8,68.3 \%$ & $8,80.6 \%$ & $\begin{array}{l}\text { retained as } \\
\text { 'agreement' }\end{array}$ \\
\hline & 15 & $\begin{array}{l}\text { Recall of children for re-assessment of caries risk } \\
\text { should be based on the clinician's assessment } \\
\text { of the child's caries risk status using the caries } \\
\text { risk assessment tool, and should not exceed } 12 \\
\text { months }\end{array}$ & $8,78.0 \%$ & $8,88.9 \%$ & $\begin{array}{l}\text { retained as } \\
\text { 'agreement' }\end{array}$ \\
\hline & 16 & $\begin{array}{l}\text { Children whose families live in a deprived area } \\
\text { should be considered as at increased risk of } \\
\text { early childhood caries when developing } \\
\text { preventive programs }\end{array}$ & $7,70.7 \%$ & - & \\
\hline & & $\begin{array}{l}\text { Revised in second round to: Children whose } \\
\text { families live in a deprived area or from lower } \\
\text { socioeconomic background should be } \\
\text { considered as at increased risk of early } \\
\text { childhood caries when developing preventive } \\
\text { programs (revised as some external reviewers } \\
\text { suggested a more detailed socioeconomic } \\
\text { background should be assessed, rather than just } \\
\text { the residential area of patient) }\end{array}$ & - & $8,77.8 \%$ & discarded \\
\hline Preventive strategies for pre-school & Ord & health education & & & \\
\hline & 17 & $\begin{array}{l}\text { Oral health education and dietary advice should } \\
\text { be incorporated into each child's general } \\
\text { well-being developmental check or at any } \\
\text { appropriate opportunity that arises }\end{array}$ & $8,97.6 \%$ & - & $\begin{array}{l}\text { retained as } \\
\text { 'agreement' }\end{array}$ \\
\hline & 18 & $\begin{array}{l}\text { The oral health of young children should be } \\
\text { promoted through multiple interventions and } \\
\text { multi-sessional health promotion programmes } \\
\text { for parents, and if possible, incorporated into } \\
\text { relevant general health promotion interventions }\end{array}$ & $8,97.6 \%$ & - & $\begin{array}{l}\text { retained as } \\
\text { 'agreement' }\end{array}$ \\
\hline & 19 & $\begin{array}{l}\text { The dental health team should deliver caries } \\
\text { prevention strategies in conjunction with } \\
\text { physical prevention techniques such as oral } \\
\text { hygiene instruction and the use of fluoride }\end{array}$ & $8,100 \%$ & - & $\begin{array}{l}\text { retained as } \\
\text { 'agreement' }\end{array}$ \\
\hline & 20 & $\begin{array}{l}\text { Oral health promotion programmes for young } \\
\text { children should be initiated before the age of } \\
3 \text { years }\end{array}$ & $8,95.1 \%$ & - & $\begin{array}{l}\text { retained as } \\
\text { 'agreement' }\end{array}$ \\
\hline & 21 & $\begin{array}{l}\text { Parents should be encouraged to take their } \\
\text { children for regular dental care as soon as the } \\
\text { first teeth erupt }\end{array}$ & $8,90.2 \%$ & - & $\begin{array}{l}\text { retained as } \\
\text { 'agreement' }\end{array}$ \\
\hline & 22 & $\begin{array}{l}\text { Teachers, community workers and lay or peer } \\
\text { educators can be effective in delivering health } \\
\text { promotion interventions and their role should } \\
\text { be considered in the development of oral } \\
\text { health promotion programmes }\end{array}$ & $8,82.9 \%$ & - & $\begin{array}{l}\text { retained as } \\
\text { 'agreement' }\end{array}$ \\
\hline & 23 & $\begin{array}{l}\text { Non-dental health professionals and lay oral } \\
\text { health workers should be provided with } \\
\text { adequate educational or training interventions } \\
\text { prior to their participation in oral health } \\
\text { promotion programmes }\end{array}$ & $8,90.2 \%$ & - & $\begin{array}{l}\text { retained as } \\
\text { 'agreement' }\end{array}$ \\
\hline & 24 & $\begin{array}{l}\text { Multidisciplinary approaches across a range of } \\
\text { settings should be taken in the delivery of oral } \\
\text { health promotion programmes }\end{array}$ & $8,87.8 \%$ & - & $\begin{array}{l}\text { retained as } \\
\text { 'agreement' }\end{array}$ \\
\hline & 25 & $\begin{array}{l}\text { The use of consistent oral health messages } \\
\text { should be promoted to support }\end{array}$ & $8,90.2 \%$ & - & $\begin{array}{l}\text { retained as } \\
\text { 'agreement' }\end{array}$ \\
\hline
\end{tabular}


Table 2 Results of the recommendations of the adapted guidelines in the two-round Delphi survey (Continued)

\begin{tabular}{|c|c|c|c|c|c|}
\hline & 26 & $\begin{array}{l}\text { Oral health promotion programmes to reduce } \\
\text { the risk of early childhood caries should be } \\
\text { available for parents during pregnancy and } \\
\text { continued postnatally }\end{array}$ & $8,97.6 \%$ & - & $\begin{array}{l}\text { retained as } \\
\text { 'agreement' }\end{array}$ \\
\hline & \multicolumn{5}{|c|}{ Dietary advice } \\
\hline & 27 & $\begin{array}{l}\text { The use of xylitol by parents or carers to reduce } \\
\text { caries in their children should be considered }\end{array}$ & $6,39.0 \%$ & $6,36.1 \%$ & discarded \\
\hline & 28 & $\begin{array}{l}\text { Oral health education on diet to parents/carers } \\
\text { and children should start early in life, } \\
\text { encouraging balanced healthy eating and a } \\
\text { reduction in both frequency and total amount } \\
\text { of sugars ingested }\end{array}$ & $8,100 \%$ & - & $\begin{array}{l}\text { retained as } \\
\text { 'agreement' }\end{array}$ \\
\hline & \multicolumn{5}{|c|}{ Use of fluoride } \\
\hline & 29 & $\begin{array}{l}\text { Community or home-based oral health } \\
\text { promotion interventions should use fluoride- } \\
\text { containing agents such as fluoride toothpaste }\end{array}$ & $9,95.1 \%$ & - & $\begin{array}{l}\text { retained as } \\
\text { 'high } \\
\text { agreement' }\end{array}$ \\
\hline & 30 & $\begin{array}{l}\text { Community-based tooth-brushing programmes } \\
\text { should include fluoride toothpaste with a } \\
\text { concentration of } 1000 \text { ppm F }\end{array}$ & $8,80.5 \%$ & - & $\begin{array}{l}\text { retained as } \\
\text { 'agreement' }\end{array}$ \\
\hline & 31 & $\begin{array}{l}\text { Community-based tooth-brushing programmes } \\
\text { should be undertaken in community-based } \\
\text { settings such as nurseries }\end{array}$ & $8,87.8 \%$ & - & $\begin{array}{l}\text { retained as } \\
\text { 'agreement' }\end{array}$ \\
\hline & 32 & $\begin{array}{l}\text { Community-based tooth-brushing programmes } \\
\text { should be undertaken with parents to create a } \\
\text { supportive environment for oral health } \\
\text { behaviour }\end{array}$ & $8,97.6 \%$ & - & $\begin{array}{l}\text { retained as } \\
\text { 'agreement' }\end{array}$ \\
\hline & \multicolumn{5}{|c|}{ Tooth-brushing } \\
\hline & 33 & $\begin{array}{l}\text { Parents/carers should brush their child's teeth } \\
\text { as soon as the first tooth appears }\end{array}$ & $9,95.1 \%$ & - & $\begin{array}{l}\text { retained as } \\
\text { 'high } \\
\text { agreement' }\end{array}$ \\
\hline & 34 & $\begin{array}{l}\text { All children should be encouraged to brush } \\
\text { their teeth under adult supervision }\end{array}$ & $8,95.1 \%$ & - & $\begin{array}{l}\text { retained as } \\
\text { 'agreement' }\end{array}$ \\
\hline & 35 & $\begin{array}{l}\text { All children should be encouraged to brush } \\
\text { their teeth under adult supervision with } \\
\text { fluoride toothpaste } \\
\text { containing at least } 1000 \text { ppm F }\end{array}$ & $8,70.7 \%$ & $8,75.0 \%$ & discarded \\
\hline & 36 & $\begin{array}{l}\text { All children should be encouraged to brush } \\
\text { their teeth under adult supervision twice a day }\end{array}$ & $8,85.4 \%$ & - & $\begin{array}{l}\text { retained as } \\
\text { 'agreement' }\end{array}$ \\
\hline & 37 & $\begin{array}{l}\text { All children should be encouraged to brush } \\
\text { their teeth under adult supervision at bedtime } \\
\text { and one other time during the day }\end{array}$ & $8,80.5 \%$ & - & $\begin{array}{l}\text { retained as } \\
\text { 'agreement' }\end{array}$ \\
\hline & 38 & $\begin{array}{l}\text { All children should be encouraged to brush } \\
\text { their teeth under adult supervision using a } \\
\text { smear (age }<2 \text { ) or small pea size (age } 2-7 \text { ) } \\
\text { amount of toothpaste }\end{array}$ & $8,82.9 \%$ & - & $\begin{array}{l}\text { retained as } \\
\text { 'agreement' }\end{array}$ \\
\hline & 39 & $\begin{array}{l}\text { Children should be encouraged to spit out } \\
\text { toothpaste and not rinse after brushing }\end{array}$ & $8,70.7 \%$ & $8,69.4 \%$ & discarded \\
\hline & 40 & $\begin{array}{l}\text { Pre-school children should be supervised by } \\
\text { an adult when brushing their teeth }\end{array}$ & $8,100 \%$ & - & $\begin{array}{l}\text { retained as } \\
\text { 'agreement' }\end{array}$ \\
\hline & 41 & $\begin{array}{l}\text { Preventive programmes comprising } \\
\text { combinations of interventions that include } \\
\text { fluoride or fissure sealants should be } \\
\text { considered for children based on their caries } \\
\text { risk status }\end{array}$ & $8,100 \%$ & - & $\begin{array}{l}\text { retained as } \\
\text { 'agreement' }\end{array}$ \\
\hline Preventive strategies for pre-school & \multicolumn{5}{|c|}{ Caries risk assessment } \\
\hline & 42 & $\begin{array}{l}\text { A formal caries risk assessment using a } \\
\text { structured caries risk assessment tool should be }\end{array}$ & $8,82.9 \%$ & - & $\begin{array}{l}\text { retained as } \\
\text { 'agreement' }\end{array}$ \\
\hline
\end{tabular}


Table 2 Results of the recommendations of the adapted guidelines in the two-round Delphi survey (Continued)

for dental assessment or emergency care, and should be re-assessed at certain interval

43 Recall of children for re-assessment of caries risk should be based on the clinician's 'agreement' assessment of the child's caries risk status using the caries risk assessment tool, and should not exceed 12 months

Diet

44 Oral health education on diet to parents/carers and children should start early in life, encouraging balanced healthy eating and a reduction in both frequency and total amount of sugars ingested

45 Parents/carers should be encouraged to limit their child's consumption of sugar-containing foods and drinks, and when possible, to confine their consumption to mealtimes

46 Children should be encouraged to limit their consumption of sugar-containing foods and drinks, and when possible, to confine their consumption to mealtimes

47 Parents and carers of children should be advised that drinks containing free sugars, including natural fruit juices, should be avoided between meals, and should never be put into a feeding bottle. Water may be given instead

48 Parents and carers should be advised not to let their child sleep or nap with a baby bottle or feeder cup

49 Members of the dental team should support and promote breastfeeding according to current $\mathrm{WHO}$ recommendations (infants should be breast fed for first 6 months, and after should receive complementary foods with continued breastfeeding up to 2 years or beyond)

50 Parents and carers should be advised that soya infant formulae are potentially cariogenic and should be used only when medically indicated

51 Sugar-free formulations of medicines should be used if available and if not parents and carers should be advised to give doses with meals and never after tooth-brushing at night

52 Parents and carers should be advised that cheese is a good high energy food for toddlers as it is non-cariogenic and may be actively protective against caries

53 Parents and carers should be assured that sugar-free snacks are unlikely to be cariogenic

54 Parents and carers should be advised that confectionery and beverages containing sugar substitutes are preferable, but should be consumed in moderation

Topical fluoride

55 The use of fluoride mouthrinse is not recommended for pre-school children due to the risk of fluoride ingestion

56 Topical fluoride varnish application (22,600 ppm F) should be given to pre-school children who are assessed as being at increased caries risk, at intervals of every 3 or 6 months 
Table 2 Results of the recommendations of the adapted guidelines in the two-round Delphi survey (Continued)

57 Fluoride varnish should be used in preference to fluoride gel for caries prevention in children who are assessed as being at high caries risk

58 Fluoride gel should not be used in children under the age of 7

Toothbrush \& Toothpaste

59 Children should have their teeth brushed with fluoride toothpaste

60 Parents/carers should be brush their child's teeth as soon as the first tooth appears

61 Toothpaste containing 1000 ppm $\mathrm{F} \pm 10 \%$ should be used by pre-school children

62 Children should have their teeth brushed, or be supervised/assisted with tooth-brushing by an adult, at least twice a day, with a smear or pea-sized amount of fluoride toothpaste

63 Children's teeth should be brushed last thing at night, before bedtime and on at least one other occasion

64 Children should be encouraged to spit out excess toothpaste and not rinse with water post-brushing

65 Eating directly after brushing should be avoided to prevent fluoride from being washed out of the mouth prematurely

66 Brushing children's teeth with powered toothbrush with a rotation oscillation can be more effective

67 Parents and carers should use a toothbrush with a small head for children

68 For pre-school children age $<2$, parents/carers of children should be encouraged to brush their child's teeth with fluoride toothpaste containing at least 1000 ppm F

69 For pre-school children age $<2$, parents/carers of children should be encouraged to brush their child's teeth twice a day

70 For pre-school children age $<2$, parents/carers of children should be encouraged to brush their child's teeth at bedtime and one other time during the day

71 For pre-school children age $<2$, parents/carers of children should be encouraged to brush their child's teeth using a smear of toothpaste

72 For pre-school children age $>2$, all children should be encouraged to brush their teeth under adult supervision

73 For pre-school children age $>2$, all children should be encouraged to brush their teeth under adult supervision with fluoride toothpaste containing at least 1000 ppm F

74 For pre-school children age $>2$, all children should be encouraged to brush their teeth under adult supervision twice a day

75 For pre-school children age $>2$, all children should be encouraged to brush their teeth under adult supervision at bedtime and one other time during the day
$8,80.5 \%$

$-$

retained as

'agreement'

$7,53.7 \%$

$6,47.2 \%$

discarded

$8,95.1 \%$

retained as 'agreement'

$8,92.7 \% \quad$ _ $\quad$ retained as 'agreement'

7, $68.3 \%$

7, $58.3 \%$

discarded

$8,92.7 \%$

retained as

'agreement'

$8,82.9 \%$

$7,70.7 \%$

discarded

$7,51.2 \%$

7, 55.6\%

discarded

6, $34.1 \%$

$6.5,50.0 \%$

discarded

8, 92.7\% $-$

retained as 'agreement'

5, 34.1\%

4, $25.0 \%$

discarded

$8,90.2 \%$

$8,82.9 \%$

retained as 'agreement'

$8,100 \%$

retained as 'agreement'

8, 63.4\%

$8,72.2 \%$

discarded

8, $90.2 \%$

retained as 'agreement'

8, 82.9\%

retained as 'agreement' 
Table 2 Results of the recommendations of the adapted guidelines in the two-round Delphi survey (Continued)

\begin{tabular}{|c|c|c|c|c|c|}
\hline & 76 & $\begin{array}{l}\text { For pre-school children age }>2 \text {, all children } \\
\text { should be encouraged to brush their teeth } \\
\text { under adult supervision using a small pea size } \\
\text { amount of toothpaste }\end{array}$ & $8,82.9 \%$ & - & $\begin{array}{l}\text { retained as } \\
\text { 'agreement' }\end{array}$ \\
\hline & \multicolumn{5}{|c|}{ Fissure sealants } \\
\hline & 77 & $\begin{array}{l}\text { Children who are assessed as being at high } \\
\text { caries risk should have resin-based fissure } \\
\text { sealant applied and maintained in vulnerable } \\
\text { pits and fissures of permanent teeth }\end{array}$ & $8,97.6 \%$ & - & $\begin{array}{l}\text { retained as } \\
\text { 'agreement' }\end{array}$ \\
\hline & 78 & $\begin{array}{l}\text { Routine application of sealants on primary molar } \\
\text { teeth is not recommended, but may be } \\
\text { considered for selected high caries risk children }\end{array}$ & $8,85.4 \%$ & - & $\begin{array}{l}\text { retained as } \\
\text { 'agreement' }\end{array}$ \\
\hline & \multicolumn{5}{|c|}{ Anti-microbial agent } \\
\hline & 79 & $\begin{array}{l}\text { The use of chlorhexidine for caries prevention } \\
\text { is not recommended }\end{array}$ & $8,68.3 \%$ & $8,75 \%$ & discarded \\
\hline & \multicolumn{5}{|c|}{ Re-mineralising product } \\
\hline & 80 & $\begin{array}{l}\text { The use of re-mineralising products (e.g. } \\
\text { CPP-ACP) can help caries prevention }\end{array}$ & $8,78 \%$ & $8,88.9 \%$ & $\begin{array}{l}\text { retained as } \\
\text { 'agreement' }\end{array}$ \\
\hline \multirow[t]{10}{*}{ Management strategies $(N=11)$} & 81 & $\begin{array}{l}\text { Primary teeth with caries progressing into } \\
\text { dentine should be actively managed with a } \\
\text { preventive, or a preventive and restorative, } \\
\text { approach as appropriate with the child's ability } \\
\text { to cooperate }\end{array}$ & $8,90.2 \%$ & - & $\begin{array}{l}\text { retained as } \\
\text { 'agreement' }\end{array}$ \\
\hline & 82 & $\begin{array}{l}\text { Restorative treatment should always be provided } \\
\text { in conjunction with a course of preventive } \\
\text { treatment }\end{array}$ & $8,90.2 \%$ & - & $\begin{array}{l}\text { retained as } \\
\text { 'agreement' }\end{array}$ \\
\hline & 83 & $\begin{array}{l}\text { If complete caries removal from a vital primary } \\
\text { molar is not possible an indirect pulp capping } \\
\text { technique should be considered }\end{array}$ & $8,87.8 \%$ & - & $\begin{array}{l}\text { retained as } \\
\text { 'agreement' }\end{array}$ \\
\hline & 84 & $\begin{array}{l}\text { A calcium hydroxide containing lining material, } \\
\text { followed by an adhesive restoration or a } \\
\text { pre-formed metal crown, should be used }\end{array}$ & $7,65.9 \%$ & $6,47.2 \%$ & discarded \\
\hline & 85 & $\begin{array}{l}\text { When preparing a Class II cavity, care must be } \\
\text { taken to avoid iatrogenic damage to adjacent } \\
\text { proximal tooth surfaces }\end{array}$ & $9,100 \%$ & - & $\begin{array}{l}\text { retained as } \\
\text { 'high } \\
\text { agreement' }\end{array}$ \\
\hline & 86 & $\begin{array}{l}\text { Use of the Atraumatic Restorative Treatment } \\
\text { approach for cavity preparation in carious } \\
\text { primary teeth should be considered as an } \\
\text { alternative, where appropriate, to conventional } \\
\text { cavity preparation techniques }\end{array}$ & $8,90.2 \%$ & - & $\begin{array}{l}\text { retained as } \\
\text { 'agreement' }\end{array}$ \\
\hline & 87 & $\begin{array}{l}\text { Minimal amount of formocresol for doing } \\
\text { pulpotomy in primary teeth should be used }\end{array}$ & $8,80.5 \%$ & - & $\begin{array}{l}\text { retained as } \\
\text { 'agreement' }\end{array}$ \\
\hline & 88 & $\begin{array}{l}\text { Amalgam, composite, resin-modified } \\
\text { glass-ionomers, compomer or preformed metal } \\
\text { crowns should be used as restorative materials } \\
\text { for cavities in primary molars; conventional } \\
\text { glass-ionomer should be avoided, where } \\
\text { possible, for Class II cavity restoration }\end{array}$ & $8,95.1 \%$ & - & \\
\hline & 88 & $\begin{array}{l}\text { Revised in second round to: Composite, } \\
\text { resin-modified glass-ionomers, compomer or } \\
\text { preformed metal crowns should be used as } \\
\text { restorative materials for cavities in primary } \\
\text { molars; conventional glass-ionomer should be } \\
\text { avoided, where possible, for Class II cavity } \\
\text { restoration (revised as some external reviewers } \\
\text { commented that amalgam should better not to } \\
\text { be used in children) }\end{array}$ & - & $8,86.1 \%$ & $\begin{array}{l}\text { retained as } \\
\text { 'agreement' }\end{array}$ \\
\hline & 89 & $\begin{array}{l}\text { Conventional glass-ionomer should be avoided, } \\
\text { where possible, for Class II cavity restoration }\end{array}$ & $7,56.1 \%$ & $8,63.9 \%$ & discarded \\
\hline
\end{tabular}


Table 2 Results of the recommendations of the adapted guidelines in the two-round Delphi survey (Continued)

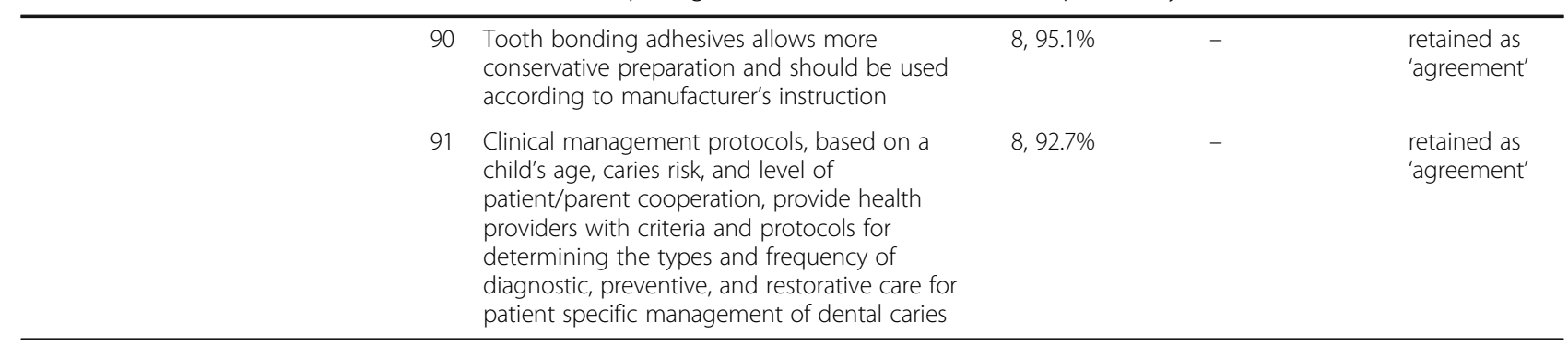

${ }^{\mathrm{a} N u m b e r s}$ are median score; ratings percentages by external reviewers with an overall median score within the top tertile (7-9)

implementation that require lots of time, expertise and resources [29]. The process is designed for a range of stakeholders, such as guideline developers, healthcare providers, consumers and policymakers at the local, national and international levels and in different healthcare sectors [10]. The process also allows users to customise the process to their own context, resource constraints and expertise. In this project, in addition to the external review process set up in the ADAPTE framework, the Delphi consensus technique was employed to gain reviewers' comments and consensus on the guideline recommendations. The developed guidelines are evidence-based with up-to-date knowledge and have gained consensus among the profession. Concerns in the acceptability and barriers in implementation are reduced.

Table 3 General view of the external reviewers on the strengths and weaknesses of the guideline

\begin{tabular}{|c|c|c|c|}
\hline No. & Statement about the view on the guideline & Median score & $\begin{array}{l}\text { Percentage of } \\
\text { score at } 4-5\end{array}$ \\
\hline 1 & $\begin{array}{l}\text { The rationale for developing a guideline, as stated in the '1. Introduction' section of the draft } \\
\text { guideline report, is clear }\end{array}$ & 4 & 73.2 \\
\hline 2 & There is a need for a guideline of this topic & 4 & 82.9 \\
\hline 3 & $\begin{array}{l}\text { The literature search is relevant and complete in this draft guideline (i.e. no key trials were } \\
\text { missed nor any included that should not have been) }\end{array}$ & 4 & 61 \\
\hline 4 & I agree with the methodology used to summarize the evidence included in this draft guideline & 4 & 63.4 \\
\hline 5 & The draft recommendations in this report are clear & 4 & 73.2 \\
\hline 6 & I agree with the draft recommendations as stated & 4 & 68.3 \\
\hline 7 & The draft recommendations are suitable for the pre-school children & 4 & 70.7 \\
\hline 8 & The draft recommendations are too rigid to apply to individual patients & 3 & 36.6 \\
\hline 9 & When applied, the draft recommendations will produce more benefits for patients than harms & 4 & 90.2 \\
\hline 10 & The draft guideline report presents options that will be acceptable to patients & 4 & 68.3 \\
\hline 11 & $\begin{array}{l}\text { To apply the draft recommendations will require reorganization of services/care in my practice } \\
\text { setting }\end{array}$ & 4 & 58.5 \\
\hline 12 & To apply the draft recommendations will be technically challenging & 3 & 26.8 \\
\hline 13 & The draft recommendations are too expensive to apply & 3 & 31.7 \\
\hline 14 & The draft recommendations are likely to be supported by a majority of my colleagues & 3 & 34.1 \\
\hline 15 & If I follow the draft recommendations, the expected effects on patient outcomes will be obvious & 3 & 39 \\
\hline 16 & The draft recommendations are the same as the current usual practice & 3 & 43.9 \\
\hline 17 & $\begin{array}{l}\text { The draft recommendations reflect a more effective approach for improving patient outcomes } \\
\text { than is current usual practice }\end{array}$ & 3 & 41.5 \\
\hline 18 & $\begin{array}{l}\text { When applied, the draft recommendations will result in better use of resources than current } \\
\text { usual practice }\end{array}$ & 3 & 26.8 \\
\hline 19 & I would feel comfortable if my patients received the care recommended in the draft guideline & 4 & 70.7 \\
\hline 20 & The draft guideline should be approved as a practice guideline & 4 & 61 \\
\hline 21 & If this draft guideline were to be approved, I would make use of it in my own practice & 4 & 63.4 \\
\hline 22 & If this draft guideline were to be approved, I would apply the recommendations to my practice & 4 & 68.3 \\
\hline
\end{tabular}

Statements were rated on a 5 -point Likert scale ( $1=$ strongly disagree; $2=$ disagree; $3=$ neutral; $4=$ agree; $5=$ strongly agree) 
A consensus approach using the Delphi technique was employed during the external review process of the guidelines. Delphi strengthened the external review process of this guideline development. In addition to external reviewers' comments and views on the draftadapted guidelines, their consensus on the guidelines' recommendations was achieved. External reviewers were members of the Hong Kong Society of Paediatric Dentistry, who were either specialists of paediatric dentistry or dental/medical practitioners with active participation in the field. This heterogeneous sample ensured that a wide spectrum of opinions of the guideline could be collected. The group consisted of 41 members in round 1 and 36 members in round 2, thus reducing the potential of selection bias of 'experts' for the Delphi process [13, 14, 30]. Moreover, the invited external reviewers are likely to be the major users of the guidelines when implemented. Involving them in the external review process using Delphi promotes ownership and acceptance of the guidelines, ultimately reducing the barrier of guideline adherence in practice in the future [31]. Involvement of the general public in the external review process could be considered in the future. They are one of the key stakeholders of the guidelines. Their input could help develop more comprehensive evidence-based guidelines with minimum barriers during implementation.

The response rate in the second round of Delphi $(52.9 \%, 36 / 68)$ dropped when compared to the first round $(60.3 \%, 41 / 68)$. Recruitment of dental practitioners in a research study is a challenge and it is also difficult to retain a high response rate in each round of Delphi $[13,14]$. Instead of employing the classical fourround Delphi, a two-round web-based Delphi was used [14]; the use of Internet avoids the need for face-to-face meetings among the external reviewers. The external reviewers can review the guidelines at different geographic locations and time.

The consensus level of the Delphi technique in the literature ranges from $51 \%$ to $80 \%$; a bench mark of $70 \%$ is used in many cases [30]. We used $80 \%$ as the level of consensus in this guideline development project. The intraclass correlation and CIs were good. Consensus was reached for a large proportion of recommendations with high inter-rater agreement between rounds.

The online implementation of the Delphi technique for external review was well received. External reviewers completed the two-round web-based Delphi external review of the guideline over a period of 5 months. They contributed extensive and supportive comments on the guidelines and the recommendations.

Not all evidence-based recommendations were accepted by the external reviewers. Although the recommendation, 'All children should be encouraged to brush their teeth under adult supervision with fluoride toothpaste containing at least $1000 \mathrm{ppm} \mathrm{F}^{\prime}$ was based on strong evidence [32], it was not able to gain agreement from the external reviewers. A number of external reviewers were concerned about dental fluorosis in relation to the use of high concentration fluoride toothpaste in a water fluoridated area like Hong Kong. This reflected that the strength of the evidence, applicability to real-life conditions and associated socioeconomic costs influenced the acceptance of recommendations. Moreover, this showed that the guideline development process was effective in identifying potential local barriers in applying research evidence to clinical practice and recommendations allowed their modification to fit local circumstances in response to reviewers' opinions.

\section{Conclusions}

Using the ADAPTE process and Delphi consensus, evidence-based clinical guidelines for caries prevention and management by caries risk assessment for preschool children in Hong Kong were developed. These guidelines can facilitate the translation of evidence into practice. The framework for developing the guidelines could be employed elsewhere.

\section{Abbreviations}

AGREE II, Appraisal of Guidelines for Research and Evaluation II instrument: HKSPD, Hong Kong Society of Paediatric Dentistry; SIGN, Scottish Intercollegiate Guideline Network (SIGN)

\section{Acknowledgements}

We would like to acknowledge the valuable involvement of all members of the panel and external reviewers. We would like to express our gratitude to Hong Kong Society of Paediatric Dentistry (project collaborator) as well.

\section{Authors' contributions}

$\mathrm{GL}, \mathrm{CM}$ and $\mathrm{CY}$ participated in the design of the study. GL commenced and coordinated the study, searched and screened the retrieved guidelines, drafted the guidelines recommendations and the guidelines, collected, analysed and transcribed the data, involved in the acquisition of data, interpreted the results and wrote the manuscript. CM and CY drafted the guidelines recommendations, ensured the accuracy and integrity of the study, contributed to the interpretation of results, and critically reviewed the draft guidelines and the manuscript. All authors read and approved the final version of the manuscript.

\section{Competing interests}

The authors declare that they have no competing interests.

\section{Author details}

${ }^{1}$ Paediatric Dentistry, Faculty of Dentistry, University of Hong Kong, 2/F, Prince Philip Dental Hospital, 34 Hospital Road, Hong Kong, China.

${ }^{2}$ Periodontology and Public Health, Faculty of Dentistry, University of Hong Kong, 3/F, Prince Philip Dental Hospital, 34 Hospital Road, Hong Kong, China.

Received: 21 December 2015 Accepted: 2 June 2016

Published online: 14 June 2016

References

1. Hong Kong Department of Health. Oral health Survey 2011: common dental diseases and oral health related behaviour. Hong Kong: Dental Services Head Office, Department of Health; 2012. 
2. Hong Kong Department of Health. Oral health Survey 2001: common dental diseases and oral health related behaviour. Hong Kong: Dental Services Head Office, Department of Health; 2002.

3. Bolin AK, Bolin A, Jansson L, Calltorp J. Children's dental health in Europe: sociodemographic factors associated with dental caries in groups of 5- and 12-year-old children from eight EU countries. Swed Dent J. 1997;21:25-40.

4. Lee GH, McGrath C, Yiu CK. Barriers to providing oral health care to pre-school children - differences between paediatric dentists' and general dental practitioners' beliefs. Community Dent Health. 2015;32:32-8.

5. Lee GH, McGrath C, Yiu CK. The care of the primary dentition by general dental practitioners and paediatric dentists. Int Dent J. 2013;63(5):273-80.

6. Field MJ, Lohr KN. editors. Clinical practice guidelines: directions for a new program. Committee to Advise the Public Health Service on Clinical Practice Guidelines, Institute of Medicine. Washington: National Academy Press; 1990.

7. Field MJ, Lohr KN. editors. Guidelines for Clinical Practice: From Development to Use. Committee to Advise the Public Health Service on Clinical Practice Guidelines, Institute of Medicine. Washington: National Academy Press; 1992.

8. Collaboration AGREE. Development and validation of an international appraisal instrument for assessing the quality of clinical practice guidelines: the AGREE project. Qual Saf Health Care. 2003;12(1):18-23.

9. Atkins D, Best D, Briss PA, Eccles M, Falck-Ytter Y, Flottorp S, Guyatt GH, Harbour RT, Haugh MC, Henry D, Hill S, Jaeschke R, Leng G, Liberati A, Magrini N, Mason J, Middleton P, Mrukowicz J, O'Connell D, Oxman AD, Phillips B, Schünemann HJ, Edejer T, Varonen H, Vist GE, Williams JW Jr, Zaza S; GRADE Working Group. Grading quality of evidence and strength of recommendations. BMJ. 2004;328(7454):490-7.

10. Fervers B, Burgers JS, Voellinger R, Brouwers M, Browman GP, Graham ID, Harrison MB, Latreille J, Mlika-Cabane N, Paquet L, Zitzelsberger L, Burnand B; ADAPTE Collaboration. Guideline adaptation: an approach to enhance efficiency in guideline development and improve utilisation. BMJ Qual Saf. 2011;20(3):228-36

11. ADAPTE Collaboration. The ADAPTE Process: Resource Toolkit for Guideline Adaptation. Version 2.0. 2009. http://www.g-i-n.net/document-store/ working-groups-documents/adaptation/adapte-resource-toolkit-guidelineadaptation-2-0.pdf/at_download/file. Accessed 12 June 2016

12. Dalkey NC, Helmer O. An experimental application of the Delphi-method to the use of experts. Manag Sci. 1963;9(3):458-67.

13. Green $B$, Jones $M$, Hughes D, Williams A. Applying the Delphi technique in a study of GPs' information requirements. Health Soc Care Community. 1999;7(3):198-205.

14. Keeney S, Hasson F, Kenna HP. A critical review of the Delphi technique as a research methodology for nursing. Int J Nurs Stud. 2001;38(2):195-200.

15. Cramer CK, Klasser GD, Epstein JB, Sheps SB. The Delphi process in dental research. J Evid Base Dent Pract. 2008;8(4):211-20.

16. Zhao D, Hu D. Barriers to translating EU and US CVD guidelines into practice in China. Nat Rev Cardiol. 2012;9(7):425-9.

17. Next Step Consortium AGREE. The Appraisal of Guidelines for Research \& Evaluation II (AGREE II) Instrument. 2009. http://www.agreetrust.org/wpcontent/uploads/2013/10/AGREE-II-Users-Manual-and-23-item-Instrument_ 2009_UPDATE_2013.pdf. Accessed 12 June 2016.

18. Scottish Intercollegiate Guidelines Network (SIGN). SIGN 83: Prevention and management of dental decay in the pre-school child. A national clinical guideline. Edinburgh: SIGN; 2005. p. 41. (SIGN publication no. 83).

19. Irish Oral Health Services Guideline Initiative. Strategies to prevent dental caries in children and adolescents: evidence-based guidance on identifying high caries risk children and developing preventive strategies for high caries risk children in Ireland. Cork: Oral Health Services Research Centre; 2009. p. 90. http://www.ucc.ie/en/ohsrc/ publications-guidelines/. Accessed 12 June 2016

20. American Academy of Pediatric Dentistry (AAPD). Guideline on caries-risk assessment and management for infants, children and adolescents. Chicago: American Academy of Pediatric Dentistry (AAPD); 2011. p. 8.

21. Programme SDE. Prevention and management of dental caries in children: dental clinical guidance. Dundee: Scottish Dental Effectiveness Programme; 2010. p. 112.

22. Irish Oral Health Services Guideline Initiative. Topical Fluorides: Evidencebased guidance on the use of topical fluorides for caries prevention in children and adolescents in Ireland. Cork: Oral Health Services Research Centre; 2008. p. 95. http://ohsrc.ucc.ie/html/guidelines.html. Accessed 15 Aug 2015
23. Ramos-Gomez F, Ng MW. Into the future: keeping healthy teeth caries free: pediatric CAMBRA protocols. J Cal Dent Asso. 2011;39(10):723-33.

24. Scottish Intercollegiate Guidelines Network (SIGN). SIGN 50: A Guideline Developer's Handbook. Edinburgh: SIGN; 2011. p. 104. (SIGN publication no. 50).

25. Woolf SH, Grol R, Hutchinson A, Eccles M, Grimshaw J. Clinical guidelines: potential benefits, limitations, and harms of clinical guidelines. BMJ. 1999:318:527-30.

26. Grol R. Successes and failures in the implementation of evidence-based guidelines for clinical practice. Med Care. 2001;39(8 Suppl 2):46-54.

27. Grol R, Thomas S, Roberts R. Development and implementation of guidelines for family practice: lessons from the Netherlands. J Fam Pract. 1995:40:435-9.

28. Stephens RG, Kogon SL, Bohay RN. Current trends in guideline development: a cause for concern. J Can Dent Assoc. 1996;62:151-8.

29. Raine R, Sanderson C, Black N. Developing clinical guidelines: a challenge to current methods. BMJ. 2005;331:631-3.

30. Hasson F, Keeney S, McKenna H. Research guidelines for the Delphi survey technique. J Adv Nurs. 2000;32:1008-15.

31. Grol R, Grimshaw J. From best evidence to best practice: effective implementation of change in patients' care. Lancet. 2003;362(9391):1225-30.

32. Walsh T, Worthington HV, Glenny AM, Appelbe P, Marinho VCC, Shi X Fluoride toothpastes of different concentrations for preventing dental caries in children and adolescents. Cochrane Database Syst Rev. 2010;1:CD007868.

33. American Dental Association Council on Scientific Affairs. Professionally applied topical fluoride: evidence-based clinical recommendations. J Am Dent Asso. 2006;137(8):1151-9.

34. Ramos-Gomez FJ, Crall J, Gansky SA, Slayton RL, Featherstone JD. Caries risk assessment appropriate for the age 1 visit (infants and toddlers). J Cal Dent Asso. 2007;35(10):687-702

35. Swedish Council on Technology Assessment in Health Care (SBU). Caries Diagnosis, Risk Assessment and Non-Invasive Treatment. A systematic review. Report no. 188. Stockholm: SBU; 2008. p. 23.

36. American Academy on Pediatric Dentistry (AAPD). Guideline on periodicity of examination, preventive dental services, anticipatory guidance/ counseling, and oral treatment for infants, children, and adolescents. Pediatric Dent. 2008-2009;30(7 Suppl):112-8.

37. Ramos-Gomez FJ, Crystal YO, Ng MW, Crall JJ, Featherstone JD. Pediatric dental care: prevention and management protocols based on caries risk assessment. J Cal Dent Asso. 2010;38(10):746-61.

\section{Submit your next manuscript to BioMed Central and we will help you at every step:}

- We accept pre-submission inquiries

- Our selector tool helps you to find the most relevant journal

- We provide round the clock customer support

- Convenient online submission

- Thorough peer review

- Inclusion in PubMed and all major indexing services

- Maximum visibility for your research

Submit your manuscript at www.biomedcentral.com/submit
Biomed Central 